\title{
The role of software Modellus in a teaching approach based on model analysis
}

\author{
Débora da Silva Soares · Marcelo C. Borba
}

Accepted: 27 December 2013/Published online: 4 March 2014

(C) FIZ Karlsruhe 2014

\begin{abstract}
We discuss some results of a study carried out over the past 4 years to investigate the role of Modellus, a software package, in the development of an approach to teaching calculus for Biology majors. The central idea of the teaching approach is to propose the analysis of a mathematical model for a biological phenomenon at the very beginning of the course, in a way that this analysis is interrelated with some of the mathematical concepts listed in the syllabus. In this paper, we focus on the role of the software during the development of one of the activities proposed to the students, the purpose of which was to discuss the relation between secant lines and the instantaneous rate of change. It was found that this software played two roles in the development of this activity: providing information about the phenomenon and the model; and acting as a trigger, making evident to the student an important aspect that contributed to his understanding. Based on our theoretical perspective of digital technology, we believe that students' interaction with the software played a fundamental role in the thinking collective composed of humans and media involved in mathematical learning.
\end{abstract}

D. S. Soares $(\bowtie)$

Pure and Applied Mathematics Department, Federal University of Rio Grande do Sul, UFRGS, Av. Bento Gonçalves, 9500-Prédio 43-111, Agronomia, Porto Alegre, RS 91509-900, Brazil

e-mail: debbie_mat@yahoo.com.br

M. C. Borba

GPIMEM, Graduate Program in Mathematics Education, Mathematics Department, São Paulo State University, UNESP, Av. 24 A, 1515, Bela Vista, Rio Claro, SP 13506-700, Brazil e-mail: mborba@rc.unesp.br
Keywords Mathematics education - Digital technology Mathematical modeling

\section{Introduction}

If you visit a first day of a calculus class ministered to Biology majors you are likely to find many of the students asking themselves why they have to take this course. And if you return on the last day of class, you will probably find that many students still have the same question. However, if you talk with scientists from different areas, they will quite likely tell you that mathematics is (at least) sometimes necessary for their area of interest. In particular, there are developing fields such as biomathematics and bioinformatics that involve heavy use of mathematics. How can these two situations coexist?

We do not know the exact answer to this question, but we can describe another similar dilemma. In Soares and Borba (2011, p. 228) we summarized it in the following way: "There is a wish that applied problems relevant to the area of the course (of Biology, for instance) be discussed from the beginning of the course, but there are no [mathematical] tools to facilitate this, because the students only know a little about functions and do not know derivatives, nor integrals, as is the case in focus here." How to deal with this dilemma is an open question.

During the last 4 years, we developed a research project aiming to investigate the role of a software package in the development of an approach to teaching calculus for Biology majors. In this paper we present and discuss some results of this research, in particular some aspects related to the role of the software during the development of one activity involving the concepts of slope of tangent and secant lines and the instantaneous and average rate of change. 
Specifically, we argue that the potential for the software to contribute significantly to the comprehension of mathematical concepts is not predetermined by the structure of the software. According to our observation, this potential is partially related to the design of the activity and to the teacher's interventions, which can contribute to raising students' awareness about the utility of certain resources of the software to work with the problem in focus.

The paper is structured as follows: we begin by presenting the central idea of the teaching approach, followed by a brief literature review about the teaching and learning of calculus; then, a description of the research methodology and the theoretical background is provided; some data is then presented related to the role of the software used, accompanied by analysis of the data; finally, we share some final considerations. We hope to provide the reader with the opportunity to reflect on the role of technology in Mathematics classrooms and some of its relations with the dilemma mentioned above.

\section{Calculus as a service subject}

Among Mathematics courses, calculus is the one that appears most frequently in the curricula of undergraduate courses. In fact, the majority of students studying calculus are not Mathematics majors (Tall et al. 2008). It usually presents a syllabus which includes the study of functions, limits, derivatives, and integrals. The emphasis given to each one of these concepts varies according to its relevance for each course (Howson et al. 1988; Biembengut and Hein 1995). This extensive presence of calculus in different courses is due to the general understanding that its contents are important for the students as a theoretical base and because it is used to represent and analyze phenomena studied in other fields (Franchi 1995). However there is contradiction involving the teaching and learning of calculus which resembles the aforementioned dilemma: despite its relevance, often the students' view regarding the course is one of fear, uncertainty, and doubt (Catapani 2001).

Similar scenarios around the world have attracted the attention of mathematicians concerned with the quality of student learning of calculus, leading to the development of research on the issue (Tall et al. 2008). According to Robert and Speer (2001), it is possible to identify two trends regarding research on the teaching and learning of calculus: one that is based, at least partly, on content and epistemological analysis of the target knowledge; and other more pragmatic, based on the "calculus reform" program.

Tall et al. (2008) presented some results of studies associated with the second trend involving digital technology. The evidence regarding the role of technology in producing changes in learning gains was mixed. This uncertainty was corroborated by papers published after the second study on digital technology and mathematics education, organized by ICMI, which also presented conflicting results (Hoyles and Lagrange 2010).

In Brazil it is also possible to find a variety of research focused on the teaching and learning of calculus. Some studies have identified students' difficulties (Olímpio Junior 2006; Godoy 2004; Melo 2002) while others have proposed approaches to teaching specific calculus concepts using technology (Barbosa 2009; Scucuglia 2006; Menk 2005). Specifically related to calculus as a service subject, Catapani (2001) reported factors related to the interest/ indifference of Geology majors regarding calculus. A critical point identified was the fact that students did not know why the course was important for their field, and, in fact, the course syllabus and teachers often failed to successfully make this link.

As we mentioned in the introduction, this is also a common situation in Biology courses. Professor Marcelo Borba has taught Applied Mathematics for Biology majors at the State University of São Paulo, Rio Claro, Brazil, for nearly 20 years. The syllabus of this Applied Mathematics course includes the study of functions, notions of limits, derivatives, and integrals, and their applications. The course can therefore be considered an introductory calculus course, and it has been the context of several studies during this period. Some of the results can be found in Borba and Villarreal (2005), who discuss the role of software in the experimental-with-technology approach (where students explore and develop activities related to calculus concepts using software) and modeling (where small groups of students choose a theme to investigate using mathematics, if appropriate). The results of the research show the possibilities of technology and how students verbalize visual insights regarding mathematical concepts. There have been many instances, during the 20 years of the introductory Biology course, in which students have also offered conjectures or refuted them based on "experimentation" using different software. There are also results showing how the modeling projects developed by the students became interesting starting points for discussion of calculus concepts that were new to them, and it helped students to see how these concepts could be applied in their field. However, the mathematics used by the students usually involves only functions, which is expected, since they are being introduced to calculus concepts. Again, the same dilemma appears in our own research focusing on different pedagogical approaches we have developed: how to use calculus concepts in modeling projects in a course in which students are learning calculus?

The pedagogical approach we investigated attempts to continue our exploration of technology based on the notion 
that it enhances visualization and experimentation and allows students to focus on conceptual issues and elaborate arguments to support their ideas (Schoenfeld 1995). On the other hand, we wanted to explore a different affordance of digital technology: the possibility of introducing complex biological problems to students earlier in their academic trajectory. This is one of the aspects related to the teaching approach we have proposed to Biology majors, described in the following section.

\section{A teaching approach}

Applied Mathematics is the only required mathematics course in the entire undergraduate program in Biology. Given this situation, this course would be students' unique opportunity to reflect on mathematics in a way that relates to their field of interest. We designed a way to overcome the aforementioned dilemma and also to broaden the relations students could establish between calculus concepts and Biology.

The core of the teaching approach we developed was the following: to propose to students the analysis of a mathematical model for a certain biological phenomenon beginning on the first day of class in a way that this analysis related to some of the mathematical concepts of the syllabus.

We decided to work with a mathematical model that could represent a certain biological phenomenon with relative accuracy. Usually, demanding accuracy from a model will demand mathematical complexity. We chose as a biological phenomenon the transmission of malaria, a disease that is caused by a parasite of the genus Plasmodium and is transmitted by a mosquito of the genus Anopheles. This disease is still prevalent in many parts of the world, including in Brazil, mainly in the northern region.

Currently, there are several models to describe the transmission of malaria, but we decided to work with one of the first ones developed to study this disease: the RossMacdonald model, which was actually important, scientifically speaking, until the 1970s. This model is composed of two non-linear ordinary differential equations (ODE). The choice of this kind of model was coherent with the course we were teaching, since ODE is a subject that relates the concepts of functions, derivatives, and integrals.

The Ross-Macdonald model includes a series of simplifications regarding the phenomenon. Besides the assumption of homogenous populations, we can cite four that can be considered the most important ones: the incubation period is discarded; the gradual acquisition of immunity in humans is ignored; human mortality is also ignored; and infected mosquitoes will remain infected until death (Basañez and Rodríguez 2004). The two main dependent variables of the model are the following: $X(t)$, which gives the number of infected humans at a given point in time $t$; and $Y(t)$, which gives the number of infected (female) mosquitoes at a given point in time $t$. These variables are related as shown in the following equations:

$$
\left\{\begin{array}{l}
\frac{d X}{d t}=\left(\frac{a}{N} \cdot p\right) \cdot Y \cdot(N-X)-g \cdot X \\
\quad \text { and, } t \in[0, T] . \\
\frac{d Y}{d t}=\left(\frac{a}{N} \cdot c\right) \cdot X \cdot(M-Y)-v \cdot Y
\end{array}\right.
$$

The main idea of this system is to describe how the population of infected humans and the population of infected mosquitoes change over time. We can interpret these equations as follows. The first equation describes how the population of infected humans changes over time. It increases every time an infected mosquito $(Y)$ bites a healthy person $(N-X)$. The odds of this person becoming infected are given by the factor $(a p / N)$, which represents the number of bites a mosquito gives each person of the population per unit of time $(a / N)$ multiplied by the probability of a human becoming infected $(p)$. On the other hand, the population of infected humans decreases as sick people $(X)$ recover, and this happens according to a recovery rate $(g)$.

The second equation describes how the population of infected mosquitoes changes over time. It increases as noninfected mosquitoes $(M-Y)$ bite infected humans $(X)$, and the odds of these mosquitoes becoming infected are given by the factor $(a c / N)$, which represents the number of bites a mosquito gives each person of the population per unit of time $(a / N)$ multiplied by the probability of a mosquito becoming infected $(c)$. The population of infected mosquitoes decreases as infected mosquitoes die according to a mortality rate $(v)$.

As it is possible to note, the analysis of this model requires attention to several details. More than that, it demands access to the solutions of the model if one wants to analyze the evolution of the phenomenon. In the case under analysis, the functions $X(t)$ and $Y(t)$ are its solutions, which means that the equations given in the system are satisfied when $X(t)$ and $Y(t)$ and their derivatives $d X / d t$ and $d Y / d t$, respectively, are substituted in the equations. Therefore, how can we expect students taking an introductory Applied Mathematics course, the majority of whom have not learned the concept of derivative, to analyze this model?

It is important to note that the analysis we propose does not involve obtaining analytic expressions of the solutions. Instead we propose a qualitative analysis, focusing on comprehension of the meaning of the equations and also on the behavior of the solutions. In fact, we do not believe it is 


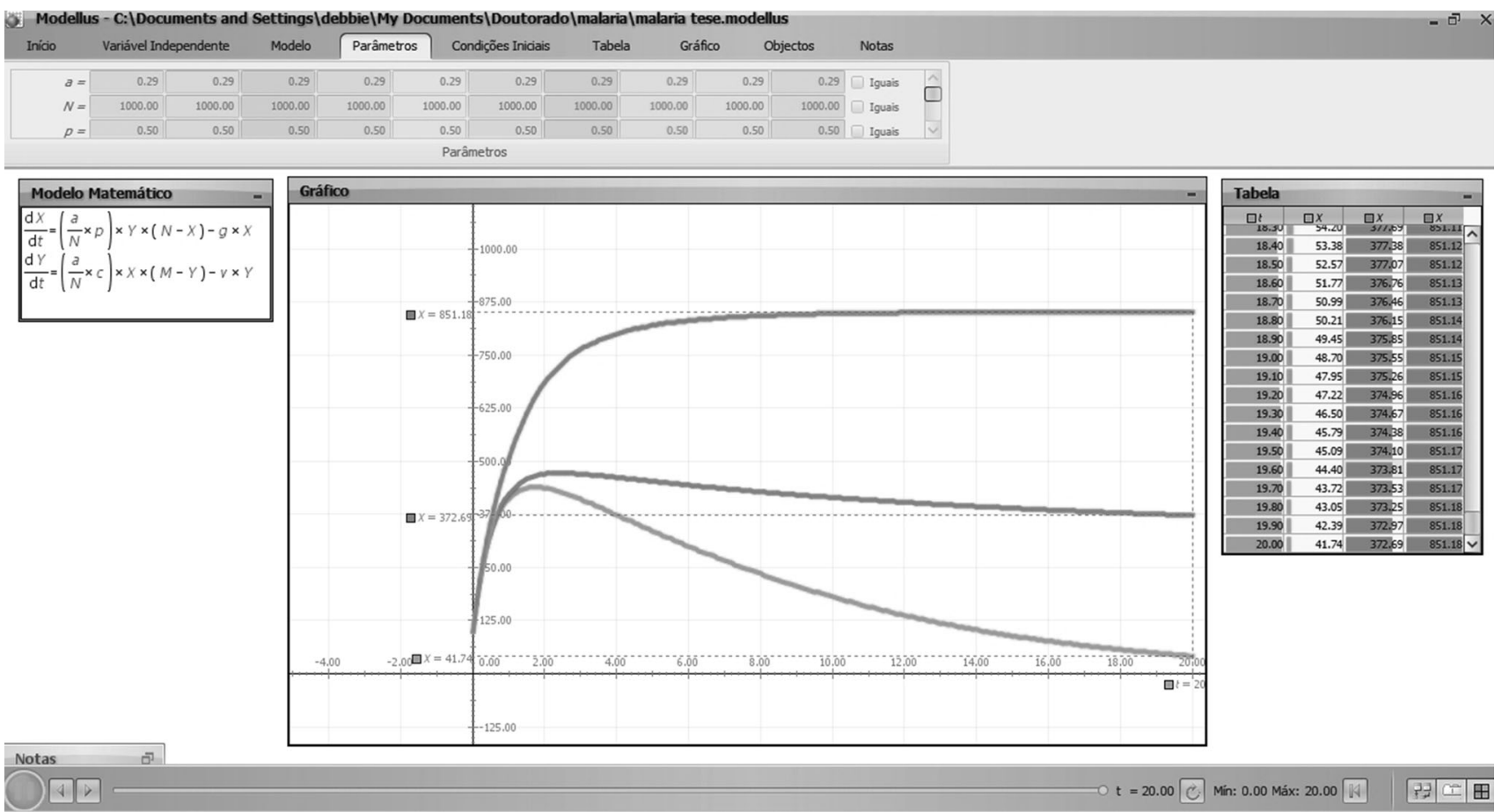

Fig. 1 Interface of Modellus

possible at present to find an analytical solution for this model, as is the case in most models involving systems of ODE. However, even with this emphasis, the students still need to have access to the solutions, and here is where the software Modellus plays its most important role.

Modellus enables one to set values for parameters and initial conditions of the model and provides graphical and tabular representations for the solutions. Multiple representations can be shown, as in Fig. 1, where it is possible to see graphs of the function $X(t)$ for three different values of one of the parameters.

The students from the Applied Mathematics course worked with Modellus during all of the semester. A set of activities was developed to guide their analysis of the model and to help them to relate this analysis to some of the mathematical concepts of the course (functions, maxima and minima, derivative, slope of the tangent line). Classes were held once a week for a 4-h period. On a normal day, up to $2 \mathrm{~h}$ of the class were based on regular use of the blackboard and/or use of GeoGebra to discuss traditional math problems. Then, following a 30-min break, students would work on the Modellus activities for about one hour and a half.

\section{Research methodology}

The research was developed following a qualitative approach, which is coherent with the aim of the research since the intention is to comprehend the role of the software in its different dimensions. The methodological approach was inspired by design research. Doerr and Wood (2006, p. 117) assert that "the first characteristic [of design research] is the deliberate intention of designing (as in the sense of engineering or architecture) an improved process or product for some purpose within a system that by necessity involves trade-offs and constraints."

We can think of the teaching approach we presented above as our product and the Applied Mathematics course as a system which is immersed in a larger system: the structure of the Biology course. Both share a set of regulations which are more or less open to negotiation. Results reported in this paper are based on data constructed during the third time the teaching approach was applied in the course. This class was an evening class composed of 22 students in the first semester of 2011.

We mentioned the third version of the teaching approach because it was applied on at least three occasions. The first one was a pilot project, and the second one was in an Applied Mathematics course in 2010. The aim of these versions was to improve the teaching approach, and this is the second characteristic of design research: "[...] it requires multiple cycles of analysis for improving the product and interpretation at multiple levels" (Doerr and Wood 2006, p. 117). According to Wittmann (1995), the design of teaching units coherent with the curricula, and the analysis of "their possible effects in different educational 'ecologies"” (Wittmann 1995, p. 363), characterize 
the framework of design sciences and has the potential to provide mathematics educators with the opportunity to fulfill various objectives.

The construction of data was based on the utilization of several sources, the third characteristic of design research. Three of the data sources we used were the following: written reports developed by the students after each class about the task they had just worked on; recordings of the computer screen of the students as well as their dialogue during the class using the software Camtasia Studio; openended interviews conducted with students at the end of the semester. The development of the data analysis revealed that these three sources of data were the most important for our purposes, which were to analyze the role of software Modellus in the development of the teaching approach.

The type of analysis proposed by design research is multiple level (Lesh and Kelly 2000), which refers to the different levels of participants in this kind of research. Usually, design research is developed based on a partnership between teachers and researchers. As a consequence, three levels of analysis are generated: (i) the level of students, who develop a series of activities proposed by the teacher and researchers, and reflect upon them; (ii) the level of teachers, who analyze and try to comprehend different aspects involved in the development of the activities by students; (iii) the level of researchers, who analyze and try to comprehend different aspects involved in the development of activities by both students and teachers.

The focus of our analysis differs somewhat from these levels. The two authors of this paper had dual roles as teachers and researchers. Multiple level analyses require a person with the sole role of observer/researcher, a teacher who develops the class, and the students. We can therefore say that, inspired by the above model, we developed a new phase, in which the intervention in the class and the analyses were more intertwined than in other studies.

We conducted a vertical analysis (Busse and Borromeo Ferri 2003), since we had two types of data: from observation (videos generated by the software Camtasia Studio) and from students' perspectives and activities (interviews and written reports). In vertical analysis, each type of data is considered as a unit and is interpreted separately. This process leads to the method of triangulation (Lincoln and Guba 1985). An important aspect to be considered is that the interpretations that emerge from each data source cannot be seen as a validation of each other, since the data is constructed in different conditions. In this sense, the aim of triangulation in our study was to broaden the understanding of a situation, based on evidence resulting from different methods.

Based on these ideas, we analyzed data identifying themes related to our research problem: analyze the role of the software in the teaching approach. Analysis was inductive (Lincoln and Guba 1985), which means categories were not defined a priori, but were constructed based on the data. In this sense, themes were identified based on students' assertions related to their experience with the software and their actions during the development of the activity. Assertions related to a similar subject or with similar content were categorized with the same code. For example, some students commented on their impressions about working with the software and the comprehension of the mathematical concepts they were studying. These assertions gave rise to the following theme: "software contributing to the comprehension of mathematical concepts." The title did not imply that we assumed the software in fact contributed to the comprehension of the concepts, but rather that the excerpts coded with that theme would contribute to its understanding.

Wittmann (1995), when discussing the notion of mathematics education as a design science, asserts that " $[. .$.$] the$ specific tasks of mathematics education can only be actualized if research and development have specific linkages with practice at their core [...]" (Wittmann 1995, p. 2). He characterizes this core with some of its components. Two of them are: "exploration of possible contents that focus on making them accessible to learners" and "development and evaluation of substantial teaching units" (Wittmann 1995, pp. 2-3).

The teaching approach we developed and the data analysis we conducted are in line with these two components of the core pointed out by Wittmann (1995). In fact, one of the aims of the teaching approach is to provide an opportunity for the students to reflect about mathematical concepts in a way that is intertwined with their field of interest. In our understanding, this is a way of making the concepts of calculus accessible to the students, since the activities brought them to a context that is familiar to Biology majors. Furthermore, our research focuses on the role of the software, which can be considered an evaluation of the teaching unit employed, as proposed by Wittmann (1995).

The importance we attribute to the investigation of the software's role in the teaching approach is closely related to our epistemological view regarding technologies, to which we will now turn.

\section{Humans-with-media}

Reflecting on the role of software in the development of the teaching approach is key since media have a central role in our view of the process of knowledge production. This notion can be encountered in the theoretical construct humans-with-media, proposed by Borba and Villarreal (2005), which was inspired by the work of Tikhomirov (1981) and Lévy (1993). Media are 
understood as technologies that are used for any kind of communication among humans. Media are seen as an active part of the process of interaction among humans, and help to constitute communication but also shape social norms and the very notion of what it means to be human. Orality, writing, and informatics have been called technologies of intelligence (Lévy 1993), and we refer to them as media.

When we think about how media are present in our activities, it is quite intuitive to think that they actually help us to do some things faster or even that they can substitute for us in some tasks. For example, it is almost always faster to use a computer to make some calculations than to use only paper and pencil. It is almost as if the computer is substitute for our own thinking processes, since all that is needed is to press some keys in a specific order. But if one analyzes this situation in greater detail, some limitations in this way of thinking can be noticed.

Tikhomirov (1981) discusses how technology influences human cognition, focusing his discussion on computers. He asserts that viewing computers as a substitute for human thinking presupposes that they reproduce the same heuristics as human reasoning. However, he argues that the heuristics used by computers and by humans are different, since computer processes are much simpler.

Furthermore, in helping humans to carry out activities more quickly and enabling them to process a larger volume of information, computers could also be said to supplement humans. However, as Tikhomirov points out, such a view only accounts for quantitative aspects of the influence of computers in human cognition and overlooks the qualitative aspects. As Borba and Villarreal (2005, p. 12) indicate, this view disregards "the fact that thinking also includes the goal one has in mind, the choice of the problem to be tackled, and changes in the problem during a process of investigation."

Tikhomirov (1981) proposes the notion of reorganization of thinking to consider the role of computers. Based on Vygotsky's theory of language as a mediator of human activity, he expands this notion of mediator to include computers. He asserts that the media one works with reorganize one's thinking in a qualitatively different way. According to Borba (2012, p. 803), "Tikhomirov presents the notion of reorganization in order to emphasize that computers do impact cognition and permeate the human mind." What does it mean, exactly, to reorganize human thinking?

According to Borba and Villarreal (2005), the role of technology in the reorganization of thinking can be conceived of as follows: what one can do with a technology that cannot be done without it or that would be unlikely to be done with another technology. Another view comes from Pea (1985), who suggests that reorganization of thinking means that the computer modifies the basic structure of one's cognitive processes, which can be understood as follows: working with a computer, one can focus one's thinking on certain aspects involved in the activity being developed. And finally, a third way to conceive of the reorganization of thinking is to consider that a person's reasoning and activity are organized according to the possibilities and restrictions offered by the media (Soares 2012).

For example, if a student wants to analyze how the parameter $c$ from the Ross-Macdonald model influences the solutions using paper and pencil, s/he would have to develop all the steps involved in the qualitative approach to work with ODE systems and to sketch the graph solutions for each value chosen for the parameter $c$. Only after doing this procedure for all values chosen for this parameter would the student be able to analyze, compare, and interpret the graphs. But if the student works with Modellus, the software will provide the graphs (using a numerical method) according to the values chosen for the parameter. The knowledge generated by such an interaction is seen as a collective production, as generated by a collective of humans-with-media.

Reflecting on this situation, it is possible to notice that: (i) with the software, the student can have access to graphical representations of the solutions and, consequently, analyze the graphs' behavior, something s/he would not be able to do without the software (or only with considerable difficulty); (ii) working with Modellus, the student can focus on the choice of the values for the parameter, on the meaning of these values, and on the analysis of the graphs, instead of focusing on the calculation and on the drawing; (iii) based on the possibilities and restrictions offered by the software, such as providing the graphs of the solutions for different values of $c$ simultaneously, students organize their thinking in the sense of analyzing the behavior of the graphs based on the visual feedback. From these three points of view, it is possible to understand that Modellus reorganizes the activity of analyzing a model.

This process of reorganization of thinking engenders a mutual shaping process, which means that human thinking is conditioned by the media one works with, and vice versa. In other words, according to Borba and Villarreal (2005), humans also shape media. For instance, some of the Biology students, while working with Modellus, used the table provided by the software only to check the values of a variable at a given point in time, assigning this function to the table and not using it for other purposes.

Borba and Villarreal (2005) propose the term "intershaping relationship" to summarize this idea. It is very interesting to note that if media shape humans and vice versa, then media-and technology in general-are 
permeated by humanity and humanity is permeated by technology. Lévy (1993) indicates that media have always been part of human history. He focuses on what he calls technologies of intelligence, techniques associated with memory and knowledge: orality, writing, and information technology.

Lévy (1993) asserts that each kind of technology of intelligence extends human memory in qualitatively different ways. Orality, for example, has a circular character, while writing brings linearity. Information technology, on the other hand, has a discontinuous character, using a language that can involve simulation, text, video, image, and instant communication (Borba and Villarreal 2005).

Based on these ideas, Borba and Villarreal (2005) suggest that knowledge is produced by a collective composed of humans as well as non-humans, that is, a collective of humans and media, or humans-with-media. In this sense, if media reorganize one's activities and thinking, if media shape one's thinking and are shaped by one's activities, and if media are intertwined with human history, they cannot have a peripheral role in knowledge production. On the contrary: they have a central role in these processes. But what is this role? This is what we want to understand regarding Modellus and the teaching approach we developed.

\section{The role of the software}

Since our aim was to analyze the role of the software Modellus in the development of the teaching approach, we present here an excerpt from the research and analyze the role of the software in the development of one of the activities proposed to the students. The aim of the activity was to discuss the geometrical interpretation of the derivative of a function in a way related to the biological phenomenon. At this point in the course, students were already familiar with the concept of derivative through the notion of instantaneous rate of change. We had discussed with the students the derivative as the slope of a tangent line to the graph of the function $f(x)=x^{2}$ in one point, using calculators, GeoGebra, and group work. The aim of the activity was mainly to propose that the students reflect once more on this interpretation, but now based on the analysis of a function for which they did not know the analytical expression, but knew only its graph and numerical values. They also had to understand this notion in relation to the biological phenomenon.

The activity had the following structure. First, the students were told to find the equation of a secant line through points $(1, X(1))$ and $(1.5, X(1.5))$, which were points in the graph of solution $X(t)$ of the Ross-Macdonald model for a certain set of parameters (Fig. 2). Using Modellus, they were to plot the graph, analyze its slope, and reflect on the possibility of relating the secant line to the average rate of change. After this, the following question was proposed: "And the instantaneous velocity (or instantaneous rate of change)? Can we relate it to the secant line? If yes, in what way? How does the tangent line relate to everything? Give a justification" (Soares 2012, p. 314). Later they were invited to reflect on what information they could extract from the tangent line regarding the phenomenon.

In the following we present an excerpt from this activity which comprises a situation that we considered to be a critical event, defined by Powell et al. (2004, p. 105), as follows:

An event is critical in its relation to a particular question which is followed by the research. Then, a situation where students present a mathematical explanation or argument, can be significant for a research question concerned with the construction of mathematical justification or proof by the students and, as such, can be identified as a critical event.

In this sense, a critical event can be understood as a situation which is intriguing for the researcher and which needs to be explained and understood. The critical event selected here by us will serve as the background for our discussion.

Kauã and Priscilla, students in the course, determined the secant line as the activity proposed and plotted it using Modellus. They got an image similar to Fig. 2, which provoked the following dialogue:

$\mathrm{K}$ : And the instantaneous velocity or instantaneous rate of change? Can we relate it to the secant line? If yes, how?

P: Hmm... the tangent line, right? Because the secant line is going to give a value [?]. The secant [line] is going to touch in only one point... Because look, if you enlarge here, look... [Priscilla applies a zoom in command to the axes of the graph—see Fig. 3]. Look, you see that, like, it is passing inside [the graph], right? K: Yes.

P: Then, like, it kind of takes two points. But the tangent [line], it is going to get smaller, do you understand? It is going to be practically right here, it is going to be practically one point only.

$\mathrm{K}$ : Which one are you talking about? The tangent line? $\mathrm{P}$ : The secant [line] is this one!

$\mathrm{K}$ : The secant [line] is this, ok.

P: The tangent [line] would be this one [?]... It is going to take practically one point like this...

$\mathrm{K}$ : I don't know how would be this line...

P: Like this look... Secant [line] practically, like... it takes... it is going to take two values, look. I only know 

the graph of $X(t)$
Fig. 2 Secant line plotted with

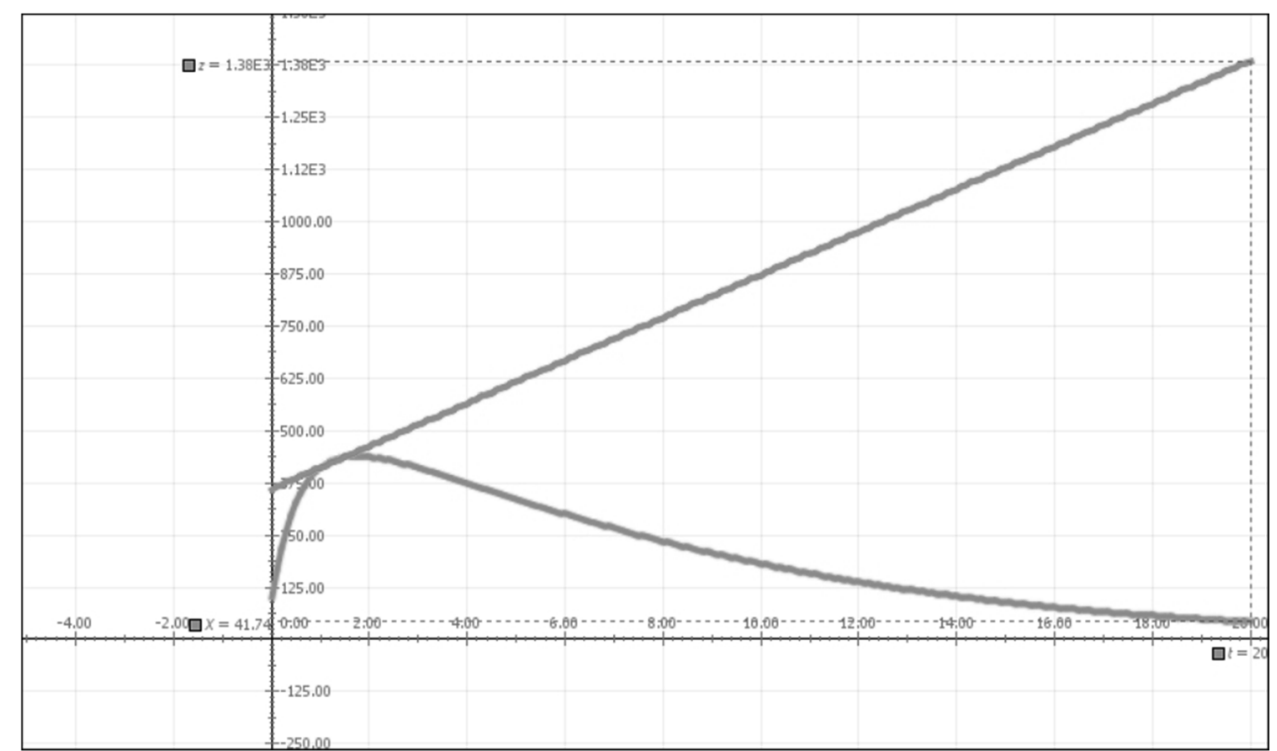

Fig. 3 Graph of $X(t)$ and the secant line with the zoom in command applied

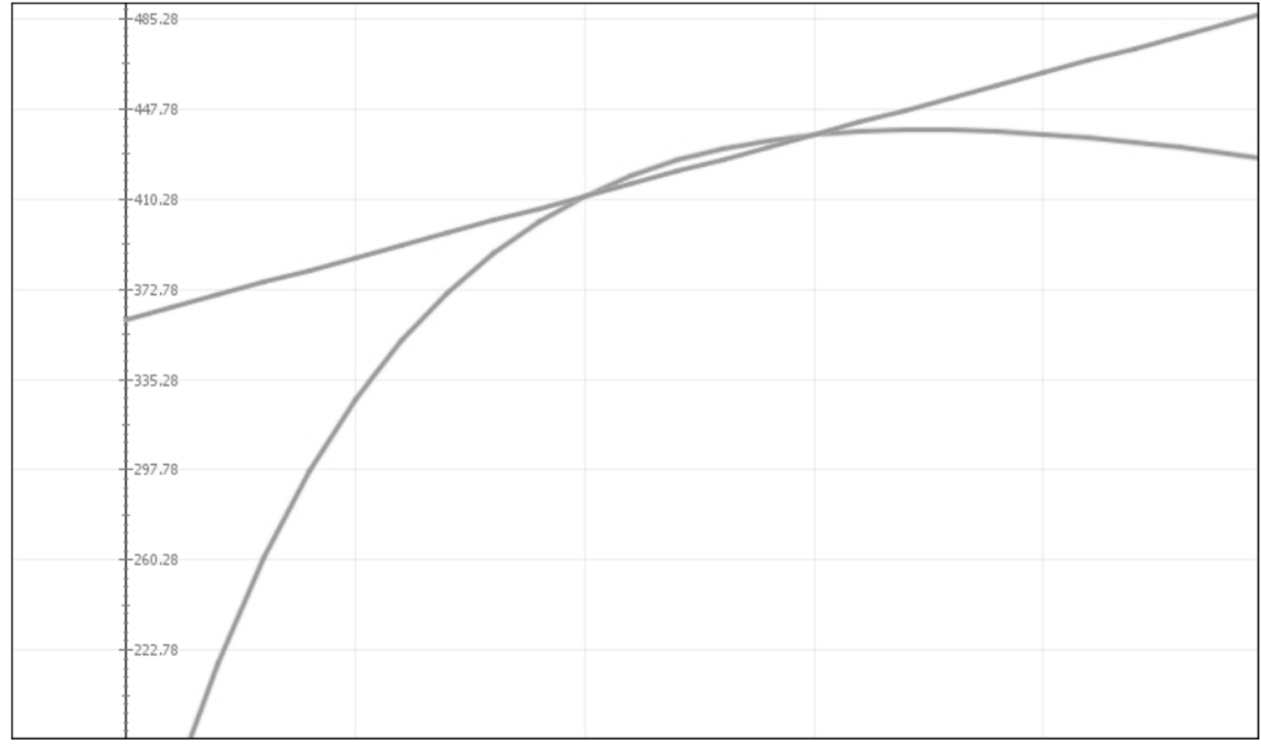

that the tangent [line] is going to be more and less like this look... it is going to touch one point, just in one point, in one point only...

K: Hmmm...

P: The secant [line], it took this value and this value...

$\mathrm{K}$ : And cross here...

P: Yes.

K: The tangent [line] doesn't. Ah, yes!

P: Did you understand?

In this first part of the excerpt, Priscilla explains to Kauã the difference between the secant line and the tangent line of a graph referring to how many points of intersection there are between each one of the lines and the graph. She uses a zoom in command (Fig. 3) to make the points of intersection between the secant line and the graph explicit to Kauã. At the end of the excerpt, they achieved an agreement: while the secant line intersects the graph at two points, the tangent line intersects the graph at only one point. Afterwards, Priscilla and Kauã developed a very interesting debate about the possibility of relating the secant line to the instantaneous rate of change, as we see in the following excerpt:

K: But how it... Let's go from the beginning, right? The instantaneous velocity... can we relate it to the secant line?

P: The instantaneous velocity will demand the time [variation] much smaller! We took the variation of zero dot five $[h=0.5] \ldots$ 
K: Yes.

P: Then it would be a secant [line], because it is going to pass inside, did you understand?

$\mathrm{K}$ : No, yes, but it is like...

$\mathrm{P}$ : The tangent [line]? It is going to...

$\mathrm{K}$ : The instantaneous variation [we] still would have to put closer there, right?

P: Yes, yes... Then as smaller the time [variation], you will get $t$...

[...]

The students start noticing that they have constructed a line using 0.5 units of time as the time interval, that is, $h=0.5$, and, as a consequence, they had a secant line. Then, they assert that, to have the instantaneous rate of change, they need a smaller time interval. Kauã tries to refine his argument in the following excerpt:

$\mathrm{K}$ : Ah, like, the more... the more instantaneous, isn't it... the line, the line isn't going to tend to get equal, aren't they going to be more similar?

$\mathrm{K}$ : Because, like... Because... if we diminish the point [time interval], like, it [the line] is not going to cross two points. If this comes here, you know...

P: Yes, the smaller... it is going to have only one line...

$\mathrm{K}$ : And the tangent line, then, like... it is going to tend to... be equal or at least similar? Because the tangent line touches in it [in the graph], doesn't it?

P: Yes, it touches... only at one point...

$\mathrm{K}$ : But then, in velocity... with the... in instantaneous velocity, the instantaneous rate of change, we will have only one point, like...

P: Yes...

$\mathrm{K}$ : Then both are not going to be very... very similar?

P: Yes, then, it is this I would like to say. Like, the instantaneous [rate of change], it is more similar with the tangent [line] than with the secant [line]. The secant [line] would be more similar with the average velocity.

In this sequence, Kauã begins by pointing out that the line "is not going to cross two points" and after that he asserts "Because the tangent line touches in it [in the graph], doesn't it?" We can infer from these sentences that he is thinking about what happens with the intersection points of the secant lines and the graph while the time interval gets smaller and smaller. Probably this reasoning led him to the conclusion that the secant lines become increasingly similar to the tangent line as the time interval gets smaller and smaller. Priscilla seems to agree with Kauã, but she says that, in her understanding, the tangent line is related to the instantaneous rate of change, and the secant line is related to the average rate of change. Kauã notices that she is saying something different and he tries to argue.

Due to limited space, we describe only the main ideas from the dialogue that followed with Kauã's arguments. He seems to focus on the difference in the time interval when one considers a tangent line or a secant line. Priscilla tries to continue his argument, but she seems to have some difficulty in expressing herself. They decide to go back to the question proposed in the activity: "How can the secant line be related to the instantaneous velocity?" (Excerpt from Camtasia, Kauã and Priscilla, Activity 6). Kauã asserts that if one can relate the average rate of change to a secant line, then one can also relate it to the instantaneous rate of change. Priscilla points out once more that, in her opinion, one can relate the instantaneous rate of change to the tangent line, but not to the secant line. The students spend some time and experience some trouble trying to convince each other of their arguments.

In the moments that followed, Kauã and Priscilla talk with their colleagues Diego (D) and Antonio (A).

D: So, in a way, it's that idea of making smaller the $t$ [variation], right? Till it tends to zero...

P: But like...

D: You use the formulae. You can use...

P: But then... it would be zero, it would be the tangent line and not the secant [line].

A: You take a secant [line] and you approximate it as...

P: Which becomes a tangent line... Yes, that's what I want to say... Like, yes, it is possible to relate, but... to me it is a tangent line, see? Then it [the secant line] turns into a tangent line, it is not a secant line anymore...

(Excerpt from Camtasia, Kauã and Priscilla, Activity 6)

As we can see in this last excerpt, Priscilla has an insight, and she finally is able to express her idea completely. Throughout the dialogue, while Priscilla said it was possible to relate the instantaneous rate of change only to the tangent line, Kauã tried to suggest that by tending $h$ to zero the secant line becomes increasingly similar to the tangent line.

In Priscilla's last sentence, when she says: "then it [the secant line] turns into a tangent line, it is not a secant line anymore...," we can infer that she noticed that for any value of $h$ they would still have an average rate of change, which is the angular coefficient of a secant line; but by making $h$ tend to zero, the secant line would become the tangent line. In her last sentence, she seemed to agree with Kauã, who used a different way of expressing himself: "[...] the more instantaneous, isn't it... the line, the line isn't going to tend to get equal, aren't they going to be more similar?"

Analyzing this excerpt, we can develop some considerations. Firstly, it is possible to observe that the reasoning 
developed by the students was based on the information about the model and the phenomenon provided by the software, both numerically and graphically. The numerical information was used by the students to determine the equation of the secant line. Although we did not quote their process of reasoning, the students found the information needed to determine the slope of secant line and the value of the function $X(t)$ in the points of intersection in the table provided by the software.

The graphical information appeared to be used more often by the students. At the beginning of the dialogue, while clarifying the difference between secant and tangent lines, we can notice that they refer to the graph ("The secant [line] is this one!"). In the rest of the dialogue, this reference is less evident in their speech, but it can still be observed ("The instantaneous variation [we] still would have to put closer there, right?").

We can also develop a consideration regarding the way the students interacted with the software. After plotting the secant line, while analyzing the differences between secant and tangent lines, we observe that Priscilla applied a zoom in command to the graph, transforming the scale to get a better view of it and highlighting the two points of intersection between the graph and the secant line. These two points were the focus of Kauã's attention later on, while developing his argument about the possibility of relating the secant line with the instantaneous rate of change ("Because... if we diminish the point [time interval], like, it [the line] is not going to cross two points. If this comes here, you know...").

On the other hand we can notice that Priscilla deals with a conflict. Throughout the debate, she seemed to have the following position: secant lines can be related to average rate of change and tangent lines can be related to instantaneous rate of change. This was confirmed in her last sentence, where she asserts that secant lines turn into the tangent line. Therefore, for her, in the limit, there are no longer any secant lines to relate to the tangent line.

Taking into account these considerations, we would like to reflect on the role of the software in the development of the activity described above.

\section{Discussion}

What is the role of the Modellus software in the development of the teaching approach, particularly in the activity we presented? This is the main question guiding the discussion of the data presented above. To develop this discussion, it is relevant to recall the words of Salomon et al. (1991, p. 8): "[...] it is not the technology alone affecting minds but the whole 'cloud of correlated variables' technology, activity, goal, setting, teacher's role, culture exerting their combined effect."
The theoretical construct humans-with-media, the basis for our discussion on technology, highlights a thinking collective of humans and media as the unit of knowledge production. This means that, although our previous discussions emphasized the central role of media in those processes, humans were obviously important actors. Most of the research based on the construct humans-with-media (Borba and Villarreal 2005; Jacinto and Carreira 2013) recognizes, like all the research in mathematics education, that students have their idiosyncrasies, as do school environments, teachers, and so on. We emphasize the role of technology, and in particular digital technology, because we believe it comprises part of the culture at this turn of the century in a way never seen before. Digital technology has changed learning, no matter what the results of our research in mathematics education indicate, in part because the Internet and mobile phones have changed the very notion of what it means to be a human being (Borba 2012).

It is from this perspective that we want to emphasize the role of the different interfaces of the Modellus software used by this pair of students. The first consideration we made above emphasized that students based their discussions on the information (graphical and numerical) provided by the software about the phenomenon and the model. Thinking with the visual feedback provided by the software, the students were able to determine the equation of the secant line and to clarify their understanding of secant and tangent lines.

In this sense, we can observe that the software played the role of providing information about the phenomenon, according to the model, in a way that contributed to students' understanding. An important aspect is that this information is provided in representations more or less familiar to the students, since the graphs are graphs of functions, and the numerical information is organized in a table. It was through these representations that the students had access to the solutions of the model.

Another important aspect is that the information provided by the software is bounded by the decisions made by students. They are the ones who choose what information they want to access. Therefore, the software plays this role in accordance with the students' instructions, which occur through their interaction with the software. In this sense, we see that collectives of students-with-Modellus are reflecting on calculus concepts in the context of a biological phenomenon.

Our second consideration was based on the observation that Priscilla used the zoom in command to highlight the two points of intersection between the secant line and the graph. It is quite interesting to observe that the students had never used this command before that day; none of the transcriptions from previous activities show students using this command. On that same day, however, we can see in 
the transcription a moment where the teacher helps the students with a doubt and uses the zoom in command. In our view, this was the moment when the students became aware of the possibilities this resource could offer when dealing with the concept of secant line.

Moreover, the use of the zoom in command became an "ally" for Kauã in terms of developing his arguments about the possibility of relating the secant line and the instantaneous rate of change. Let's analyze again part of their dialogue:

$\mathrm{K}$ : Because, like... Because... if we diminish the point [time interval], like, it [the line] is not going to cross two points. If this comes here, you know...

P: Yes, the smaller... it is going to have only one line...

$\mathrm{K}$ : And the tangent line, then, like... it is going to tend to... be equal or at least similar? Because the tangent line touches in it [in the graph], doesn't it?

P: Yes, it touches... only in one point...

$\mathrm{K}$ : But then, in velocity... with the... in instantaneous velocity, the instantaneous rate of change, we will have only one point, like...

P: Yes...

$\mathrm{K}$ : Then both are not going to be very... very similar?

We observe that Kauã refers to the intersection points three times in his argumentation. It seems that based on the visual feedback provided by the software (Figs. 2, 3), and the interaction through the zoom in command, Kauã thought with the software creating an image composed of at least two aspects: the decreasing time interval and the two points of intersection getting closer. These formed the basis for his conclusion that the secant line would get more similar to the tangent line.

This situation provides evidence that Kauã and the software had become a thinking collective (Lévy 1993), in the sense that the software had an active presence in Kauã's reasoning process. It seems, in fact, that the software played a role of a trigger, through the use of the zoom in command, highlighting an aspect that could have gone unnoticed to Kauã. In this sense, we claim that the software contributed to the comprehension of the instantaneous rate of change and its relation with the slope of secant and tangent lines.

As we mentioned at the beginning of the last section, the students worked with this activity after discussing similar ideas in class with the teacher based on the function $f(x)=x^{2}$. It is possible, then, that this discussion also influenced the reasoning developed by Kauã, enriching the thinking collective with the influence of other actors (teachers, colleagues, GeoGebra software).

On the other hand, we observed Priscilla's dilemma regarding the same question of the relationship between the secant line and the instantaneous rate of change. For her, the secant lines turn into the tangent line, meaning that, in the limit, there are not secant lines to be "related" to the instantaneous rate of change. This conflict may be associated with the enunciation of the activity or with her understanding of the concept of limit. Researches such as Olímpio Junior (2006) and Melo (2002) indicate that students have difficulties in understanding the concept of "tending to." It is very difficult to assert from our data which is the case. At the same time it is not difficult to argue that both could be true.

In fact, we observed that this activity was quite demanding for the students. As a counterpoint to the discussion, we can say: of the six pairs of students who were video-taped, Kauã and Priscilla were the only ones who interacted with the software beyond merely plotting the graph of $X(t)$ and the secant line. In the other videos, we noticed that the students did not interact further with the software. They discussed the proposed questions, but they did not move the mouse, nor did they move the graph (as they usually did in other activities), nor did they refer to the graph on the screen during their dialogue; it seemed as if the software was not there. Why did this happen?

We propose a tentative answer: the activity demanded a different kind of graph analysis compared with the other activities students had engaged in up until that moment-a local analysis of the graph instead of a global one. Thus, although they had worked with Modellus throughout the semester, they had never been faced with the need to develop a local analysis, and therefore did not become aware of the possibilities provided by the software to work with this activity.

This explanation is in line with what Artigue (2002) argues in a study involving nine students using a graphing calculator to analyze the graph of a function and make conjectures about it. The standard presentation of the graph in the calculator screen did not show an accurate image of it. Although all the students had been working with the calculator in and out of school for 1 year, only two students were successful in using a zoom out command to achieve the correct view of the graph. According to her, this does not mean a cognitive inability of the students, and in our understanding, this also does not mean that the calculator was not part of their thinking collective, but simply they had not been faced with the need to develop this kind of activity.

We believe that this overall picture of the six pairs of students engaged in this activity suggests that the development of awareness regarding the possibilities and restrictions offered by the software is not something that happens suddenly. It also seems to point to the need to revise the activity, which leads us to the next natural step in design research (Wittmann 1995): the beginning of a new cycle of development and analysis of our teaching approach. 


\section{Final considerations}

As we reported in our discussion section, evidence of an active role of Modellus was observed, and we identified two roles of the software in the development of the activity presented: (i) providing information about the phenomenon and the mathematical model with representations more or less familiar to the students; (ii) as a trigger, making evident an important aspect for the development of a sequence of reasoning. In this sense, we could say that Modellus became an active participant in the learning of the one student and also that it contributed to the comprehension of the concept of instantaneous rate of change and its relation to secant and tangent line. However, we also pointed out one conflict: the same interactions developed with the software were not sufficient to enrich the understanding of the other student about the same concept.

The considerations we have made suggest that the role of software is closely related to the design of the activities, which may or may not enhance the possibilities and limitations of the software. They also reinforce the ideas presented by Salomon et al. (1991), who emphasized the importance of considering the different aspects that can be involved in the analysis of a phenomenon. Indeed, we observed that the same activity and the same interactions with the software generated different reactions and understandings from different students, which points to other factors involved in this process that we have not yet taken into account.

We have no intention of saying that this approach (or any other) will make it possible for all students in every class to learn basic calculus concepts. However, we can conclude that the Modellus software represents a potentially fruitful path for incorporating technology into a Math class for all; as means of starting the course with a challenging, albeit complex, biological problem for all; and as means of enabling learning for some in the classroom. Our expectation is that some students learn with GeoGebra, others with the explanation of the teacher using the blackboard, others with Modellus. Our challenge is to improve the design of the pedagogical sequence to help students interact with Modellus in a way that enriches their thinking collective. While the results of this qualitative study cannot be generalized, they show the potential and the possibility of this pedagogical approach that emphasizes the production of knowledge developed by students-with-Modellus. We believe that this approach, which enabled learning for a few, could be one more option to be researched for courses similar to the one described in this paper.

Acknowledgments Although they are not responsible for the content, we would like to thank Anne Kepple and Níccholas Vidal for comments on earlier versions of this paper.

\section{References}

Artigue, M. (2002). Learning mathematics in a CAS environment: The genesis about a reflection about instrumentation and the dialectics between technical and conceptual work. International Journal of Computers for Mathematical Learning, 7(3), 245-274.

Barbosa, S. M. (2009). Tecnologias da Informação e Comunicação, Função Composta e Regra da Cadeia. Doctoral Dissertation, Universidade Estadual Paulista, Rio Claro, SP.

Basañez, M.-G., \& Rodríguez, D. J. (2004). Dinámica de transmisión y modelos matemáticos en enfermedades transmitidas por vectores. Entomotropica, 19(3), 113-134.

Biembengut, M. S., \& Hein, N. (1995). Uma proposta para o ensino de Cálculo. Temas \& Debates, VIII(6), 44-59.

Borba, M. C. (2012). Humans-with-media and continuing education for mathematics teachers in online environments. ZDM - The International Journal on Mathematics Education, 44(6), 801-814.

Borba, M. C., \& Villarreal, M. E. (2005). Humans-with-media and the reorganization of mathematical thinking: Information and communication technologies, modeling, experimentation and visualization. New York: Springer.

Busse, A., \& Borromeo Ferri, R. (2003). Methodological reflections on a three-step-design combining observation, stimulated recall and interview. ZDM - The International Journal on Mathematics Education, 35(6), 257-264.

Catapani, E. C. (2001). Cálculo em Serviço: um estudo exploratório. Bolema, 14(16), 48-62.

Doerr, H., \& Wood, T. (2006). Pesquisa-Projeto (design research): aprendendo a ensinar Matemática. In M. C. Borba (Ed.), Tendências Internacionais em Formação de Professores de Matemática. Belo Horizonte: Autêntica.

Franchi, R. (1995). Cursos de Cálculo: uma proposta alternativa. Temas \& Debates, VIII(6), 39-43.

Godoy, L. F. S. (2004). Registros de Representação da Noção de Derivada e o Processo de Aprendizagem. Master's Dissertation, Pontifícia Universidade Católica de São Paulo, São Paulo.

Howson, A. G., et al. (1988). On the teaching of mathematics as a service subject. In A. Howson, J.-P. Kahane, P. Lauginie, \& E. Turckeim (Eds.), Mathematics as a service subject (pp. 1-19). Cambridge: Cambridge University Press.

Hoyles, C., \& Lagrange, J.-B. (Eds.). (2010). Digital technologies and mathematics teaching and learning: Rethinking the terrain. New York: Springer.

Jacinto, H., \& Carreira, S. (2013). Beyond-school mathematical problem solving: A case of students-with-media. In A. M. Lindmeier \& A. Heinze (Eds.), Proceedings of the 37th conference of the international group of psychology of mathematics education (PME) (Vol. 3, pp. 105-112), Kiel, Germany.

Lesh, R., \& Kelly, A. (2000). Multi-tiered teaching experiments. In A. Kelly \& R. Lesh (Eds.), Handbook of research in mathematics and science education (pp. 197-230). Mahwah: Lawrence Erlbaum.

Lévy, P. (1993). As Tecnologias da Inteligência: o futuro do pensamento na era da informática. Rio de Janeiro: Editora 34.

Lincoln, Y. S., \& Guba, E. G. (1985). Naturalistic inquiry. Newbury Park: Sage.

Melo, J. M. R. (2002). Conceito de Integral: uma proposta computacional para o seu ensino e aprendizagem. Master's Dissertation, Pontifícia Universidade Católica de São Paulo, São Paulo.

Menk, L. F. F. (2005). Contribuições de um Software de Geometria Dinâmica na Exploração de Problemas de Máximos e Mínimos. Master's Dissertation, Universidade Estadual de Londrina, Londrina, PR. 
Olímpio Junior, A. (2006). Compreensões de Conceitos de Cálculo Diferencial no Primeiro Ano de Matemática - Uma Abordagem Integrando Oralidade, Escrita e Informática. Doctoral Dissertation, Universidade Estadual Paulista, Rio Claro, SP.

Pea, R. (1985). Beyond amplification: Using the computer to reorganize mental functioning. Educational Researcher, 20(4), 167-182.

Powell, A. B., et al. (2004). Uma Abordagem à Análise de Dados de Vídeo para Investigar o Desenvolvimento de Idéias e Raciocínios Matemáticos de Estudantes. Bolema, 17(21), 81-140.

Robert, A., \& Speer, N. (2001). Research on the teaching and learning of calculus/elementary analysis. In D. Holton (Ed.), The teaching and learning of mathematics at university level: An ICMI Study (pp. 283-299). Netherlands: Kluwer.

Salomon, G., et al. (1991). Partners in cognition: Extending human intelligence with intelligent technologies. Educational Researcher, 20(3), 2-9.

Schoenfeld, A. (1995). A brief biography of calculus reform. UME Trends, 6(6), 3-5.

Scucuglia, R. (2006). A Investigação Do Teorema Fundamental do Cálculo com Calculadoras Gráficas. Master's Dissertation, Universidade Estadual Paulista, Rio Claro, SP.
Soares, D. S. (2012). Uma Abordagem Pedagógica Baseada na Análise de Modelos para Alunos de Biologia: qual o papel do software? Doctoral Dissertation, Universidade Estadual Paulista, Rio Claro, SP.

Soares, D. S., \& Borba, M. C. (2011). Fenômeno Biológico, Sistema Dinâmico e Noções de Cálculo I: uma proposta. In L. M. W. de Almeida, J. L. Araújo, \& E. Bisognin (Eds.), Práticas de Modelagem Matemática na Educação Matemática (pp. 227-247). Londrina: Eduel.

Tall, D., Smith, D., \& Piez, C. (2008). Technology and calculus. In M. Kathleen Heid \& G. M. Blume (Eds.), Research on technology and the teaching and learning of mathematics (Vol. I, pp. 207-258). New York: Information Age.

Tikhomirov, O. K. (1981). The psychological consequences of computerization. In J. V. Wertscsh (Ed.), The concept of activity in Soviet psychology (pp. 256-278). New York: M. E. Sharpe.

Wittmann, E. C. (1995). Mathematics education as a 'design science'. Educational Studies in Mathematics, 29, 355-374. 